\title{
Teaching the English Article System Using the Communicative/Structural Approach
}

\begin{abstract}
:
Teaching Grammar has moved from focusing on the grammatical structures and combinations using a direct and explicit instruction to emphasizing communication and developing the communicative skills. Like all the grammatical aspects, the English article system is taught following the same perspective. Articles, however, are unstressed, which makes them very difficult, if not impossible, for non-native speakers to detect and eventually learn. Direct explanation of their rules is necessary, as they are hard to be heard and cannot be taught following the Communicative Approach solely. The present paper is intended to show how the Communicative/Structural Approach can be applied in the classroom to teach in general and teach the English article system particularly. We will give a full account of the data obtained during the process of our research which seeks to examine the effectiveness of the Communicative/Structural Approach. We will present the teachers' views about the usefulness of incorporating the Communicative/Structural Approach in the teaching of articles as well.
\end{abstract}

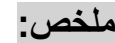

تم تغيير تدريس قواعد اللغة من التركيز على البنى والتركيبات

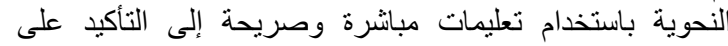

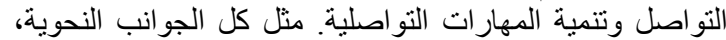

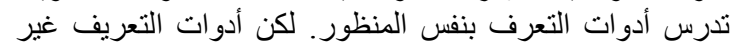

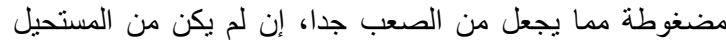

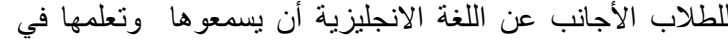
نهاية المطاف. التفسير المباشر لقوان الاعد استعمال أدوات التهات التعريف

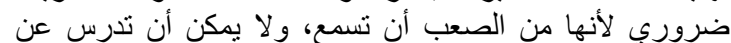

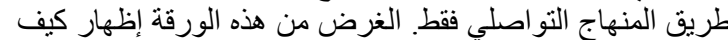

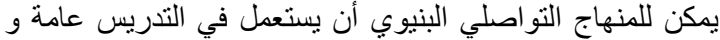
تدريس أدوات التعريف خاصة. سنقدم كذللك وصفا كاملا للبيانات

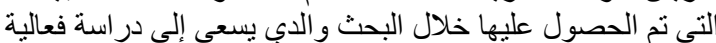

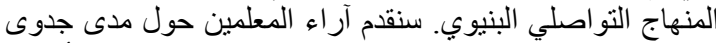

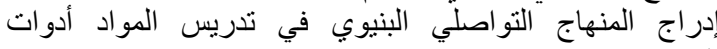

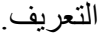

Introduction :

Teaching languages is a never ending process as well as a debate. Several language teaching approaches and methods have appeared based on some language teaching theories. Yet, there are always shortcomings that make other linguists and researchers consider new theories and practices that might help ameliorate or underlie a new approach or method. Part of teaching anylanguage is teaching its grammar. However, not all the grammatical aspects are alike, either in nature or function, which results in varying the materials,techniques, and method to 
be used in accordance with each grammatical aspect. Teaching the English article system conforms to this situation. As some researchers (for example, Master, 1994) believe that it should be taught naturally following the Natural Approach, others (for example, Ekiert, 2004) argue that it should be taught systematically and through grammatical instruction.

In this paper, another approach is introduced that is the Communicative/Structural Approach. We will cast light on its most important aspects and principles. We will also tackle its immense importance and advantages in teaching the English article system. This will be determined by the results displayed in the present paper summarizing all the findings of our study.

\section{Teaching and Learning Articles}

According to Ekiert (2004), learning articles is one of the areas that English as a second language learners find many difficulties with. Master (1994: 229) states that "several researchers consider the articles system to be unlearnable and therefore unteachable ..." and "... can only be acquired through natural exposure to the language". It is believed that language should be presented in a comprehensible and natural input (spoken) where students grasp the different structures and knowledge needed for communication in a low-risk environment, or what is called the Natural Approach. However, articles, as Ekiert (2004: 1) explained "are ... unstressed and consequently are very difficult, if not impossible, for a [non-native speaker] to discern, thus affecting the availability of input in the spoken mode". Without any direct explanation of their rules, articles would rather take a long time to be learned.

This has lead researchers to consider the importance of explicit explanation of the rules, and shift back to the Structural Approach, yet in a communicative frame. In other words, a Communicative/Structural Approach where learners will deal with the different rules underlying articles in natural, authentic and meaningful contexts which help in developing their communicative skills as well.

\section{The Communicative/Structural Approach}

The Communicative/Structural Approach is a recent adapted approach in the area of language teaching in which, positive and effective principles and aspects of both the Communicative Approach and Structural Approach are adopted and combined to form a more practical and efficient approach. We are going to define the Communicative/Structural Approach, present its major characteristics and explain its importance in the teaching of articles.

\subsection{Definition of the Communicative/Structural Approach}

The concept of the Communicative/Structural Approach is made up of two key words that are communicative and structural.

Communication implies giving and taking, sending and receiving, in other words sharing and exchanging ideas with others or passing a given 
information, fact, idea, or concept, through interaction in which three elements are essential: participants, information being communicated and instruments used. The Merriam-Webster Dictionary (2015) defines communication as "the act or process of using words, sounds, signs, or behaviors to express your ideas, thoughts, feelings, etc., to someone else". Communication is, then, a process through which mutual understanding is reached. It enables people to exchange information and is the act of uniting and connecting people (Business Dictionary, communication: 2016). On the whole, communication is the means of success of any transaction that requires more than one person.

As for the word structure, it is in turn defined by the Merriam-Webster dictionary (2015) as "the way something is built or organized: relating to the structure of something". According to the Free Dictionary (2016), it is "connected with systematic structure in a particular field of study, such as Linguistics or the behavioral sciences". When we talk about the structure of something, we are referring to the way it is built.

The Communicative/Structural Approach is based on both concepts (Communication and structure). Therefore, it focuses on building students' communicative skills as well as the linguistic one. Communicative tasks such as role playing, guessing games and creating stories are involved in the process of teaching any given grammatical structure. It takes into account integrating those communicative tasks to deliver different grammatical structures or linguistic information in an attempt to boost four-fold communicative and language skills, and most importantly it lays the foundation of grammar.

\subsection{Characteristics of the Communicative/Structural Approach}

The Communicative/Structural Approach is learning to communicate and learning about the language. It is a combination of two important notions that are the communicative aspect which is adopting creative pedagogical ideas from other approaches that can suit a wide range of learners' levels, needs and learning styles. The structural aspect emphasizes the mastery of grammar by presenting and explaining different grammatical structures and rules which govern the accuracy of any language. Accuracy is achieved when the grammar of the language is mastered. To guarantee a successful instruction of the grammatical rules, it is proposed to teach the grammatical patterns systematically. Following the Communicative/Structural Approach, the tutor is required to teach grammar deductively. Grammar is the backbone of the language and is responsible for its correctness. That is the reason why learning grammatical rules and patterns is of a high importance in learning any language. The Communicative/Structural Approach focuses on learning those structures exhaustively and systematically through direct instruction, presentation and explanation.

Authentic and meaningful communication as well as learning the grammatical structures are the goal of classroom activities and tasks. One needs 


\section{Dounia SAADI}

first to identify what a task is. Communicative tasks appeared and developed in the two last decades (Nunan, 1991: 279) being defined as "[...] classroom activit[ies] or exercise[s] that [have] an objective attainable only by the interaction among participants, a mechanism for structuring and sequencing interaction, and a focus on meaning exchange ..." which means that learners have to collaborate and work together in order to finish an assignment and achieve authentic communication. A task is also defined as "any activity or action which is carried out as the result of processing or understanding language (i.e., as a response). For example, drawing a map while listening to a tape, listening to an instruction and performing a command, may be referred to as tasks" (Richards, Platt, \& Weber, 1985, p. 289, as cited in Nunan, 1991: 280). Hence, communicative tasks help in developing the communicative skills and introducing different grammatical and linguistic structures. They are also beneficial in the sense that they have real purposes as they deal with real life contexts. This implies that students learn to face everyday life situations beside the grammatical knowledge required in each. Students are proved to be more motivated and engaged when they are asked to accomplish relevant tasks.

The Communicative/Structural Approach is grounded on the idea that the learner is an important and active participant as well as an undeniable source of information because $\mathrm{s} /$ he already has some existent background knowledge and is therefore able of sharing with others. "The implication for the learner is that he should contribute as much as he gains, and thereby learn in an independent way" (Breen and Candlin, 1980, p.110). In the Communicative/Structural Approach students are expected to interact with each other (helping low ability students with the language develop ideas, correct errors, and share different cultures with each other) as well as with their teacher. The latter's role is perceived to be a reliable source of information. The teacher, in the Communicative/Structural Approach, plays another role that is his first duty, instructing and teaching. This approach, as previously, mentioned emphasizes learning the grammatical structures in addition to the communicative aspects related to the language. In that way, the teacher has to explain the rules and grammatical patterns underlying different structures through direct clarification and systematic instruction. This adds another role which is that of teacher and instructor. One can conclude that the Communicative/Structural Approach is partly learner-centred and partly teacher-centred, in which both participants are considered equally important and essential for learning to take place. Marginalizationof any of them leads to a failure in the process of teaching and learning any particular structure.

As for the materials used in the classroom, they are considered to be an influential tool in enhancing interaction and they are highly imperative in raising the students' motivation to use the language. For example, it is more interesting to them to use a slideshow to teach them about phrasal verbs than 
writing a list on the board and telling them about their meanings. The Communicative/Structural Approach advocates the use of authentic and meaningful materials in the classroom. Cathcart argues that "... classroom language models must be based on authentic native-speaker/native-speaker discourse". In his article, he quantifies "the topics, utterance functions, and structures ... to show that simulated excerpts may serve to mislead students about the nature of everyday interactions". (1989: 105) Therefore, the language to be focused on in the classroom needs not be either unnatural or decontextualized. "Some [researchers] argued that classroom activities should as far as possible mirror the real world and use real world or "authentic" sources as the basis for classroom learning" (Richards, 2006: 20). Meaningful practice of the language, according to Richards "refers to an activity where language control is still provided but where students are required to make meaningful choices when carrying out practice". The Communicative/Structural Approach involves a variety of games, role plays, simulations, and task-based communication activities that help achieve authenticity and meaningfulness.

\subsection{Importance of the Communicative/Structural Approach}

The Communicative/Structural Approach has been founded to deal with the shortcomings of both the Structural and Communicative Approaches. Opponents of the Structural Approach argue that it is suitable for lower class students only (beginners), in which structures are merely learnt overlooking the communicative aspects and functions of the language which cannot be covered by grammar. Therefore, it highlights accuracy rather than fluency. Furthermore, it places too much demand on the teacher and marginalizes the role of the student because it is a teacher-centred approach, leaving no room for learners' innovation or a chance to express their ideas and thoughts.

On the other hand, the Communicative Approach is criticised for ignoring grammar and the different structures underlying a correct use of the language as well as its instruction. It is perceived that there is no need to emphasize the correction of grammatical errors. This leads us to consider another deficiency in the Communicative Approach, which is focus on fluency rather than accuracy. This approach is also proved to be unsuitable for beginners. Learners with low abilities find it discouraging to participate in an oral task as it requires fluency. They need first some guided and controlled practice following a grammatical instruction.

The Communicative/Structural Approach takes into account all these deficiencies and solves the problems hanging around them. It is helpful in language teaching in that:

- It focuses on the mastery and understanding of fundamental structures and their functions. Thus, interest is also laid on the functional and 
communicative value of the language developing fluency as well as accuracy.

- It teaches fourfold skill mainly vocabulary, listening, speaking, and reading.

- It develops the students' confidence in interacting with the others.

3. The Place of the Communicative/Structural Approach in the Teaching of the English Articles

The present paper deals with our study carried out based on all that have been said about the Communicative/Structural Approach. Its application in teaching and learning the English article system is an attempt to highlight the effectiveness of that approach in teaching grammar, specifically, articles. This study sets out to investigate the usefulness of systematic teaching of the English article system using a Communicative/Structural Approach at the Department of Letters and English, University "Des Frères Mentouri", Constantine. We hypothesise that if the English article system is taught systematically and using the Communicative/Structural Approach, students would improve their understanding and use of articles. The hypothesis is verified by means of a Pre-test/Post-test, Control group/Experimental Group design as well as a Teachers' and Students' Questionnaire.

\subsection{Description of the Experiment}

In order to test our hypothesis, we opted for a Pre-test/Post-test, Control Group/Experimental Group Design in addition to a Teachers' Questionnaire and a Students' Questionnaire. The experimental design was to test the students' prior knowledge and actual use of articles and compare it to the learned grammatical competence after the instruction (comparing the performance of the Experimental Group and Control Group). Moreover, the Teachers' questionnaire was handed in to collect data about the teachers' views about the Communicative/Structural Approach as well as its implementation in teaching grammar, more specifically, articles. As for the Students' Questionnaire, it was to set light on the students' awareness of their own learning.

The sample of our study was chosen at random from the whole population of second year students, counting 50 participants. The latter were divided into two groups: one Experimental Group containing 25 students and an equally numbered group that is the Control Group. The subjects were taught articles using two different approaches for a period of two weeks. They were not aware of the aims of our research so as to guarantee authentic and unbiased answers. The teaching part started in the second semester after assessing all the students' use of the articles in order to assess their actual understanding and level (which is the aim behind conducting the pre-test).

After sitting for the pre-test, the Control Group students were taught articles following one of the Communicative Approach's main principles, that 
is in a natural context, dealing with authentic discourse both written and oral in order to develop the communicative skills of the learners. The first step in the first session was introducing articles through songs. The learners listened to the song "Young Hearts Run Free" by Candy Staton first. As a warm up, they had to write down whatever they heard. That was one way to see whether they could notice articles being articulated by native speakers. Then, they were given worksheets with article gaps. The students were instructed to write the article whenever they heard it. After listening to the song twice and filling the gaps, they worked in pairs verifying and correcting their peers' answers and there was a class discussion later, it was not traditional though. The students sang along and whenever they reached a gap they stopped to answer all together. The reasons behind each answer were asked of the students and they had to guess the rules of use themselves as well as explaining them to each other. The second song "It's My Life" by Bon Jovi was also dealt with like the previous one: writing down all the lyrics, filling the article gaps, peer correction and class discussion. The whole activity lasted for 40 minutes. The motives of using songs to introduce the lesson "Articles" to the students are several, naming few:

- Breaking the ice and motivating the learners to deal with the given grammatical aspect in a fun way,

- Introducing the English article system in an authentic discourse by native speakers,

- Listening to how native speakers pronounce articles and check on the students' understanding,

- Improving the social skills and communication among the learners and between them and their teacher.

The second step was dealing with the written discourse and the students' ability to grasp the rules after analyzing an authentic discourse again. The students were given an excerpt taken from "Frankenstein, or, the Modern Prometheus" by Mary Wollstonecraft Shelley. The calss was divided into five sub-groups of five. One student from each group volunteered to read to the other four in the same sub-group. The learners were asked to identify all the words that precede every noun in the text and circle all the articles. After that they had to explain each article instance and come up with the rules underlying the article use. After working on the assignment for 40 minutes and because time was up, the students were asked to finish the task together after the class and make further research about the English article system.

In the second session, the same control group students sat in their former groups and a class discussion was held with the groups debating and explaining their answers. At the end, a set of rules was agreed on by the five sub-groups and written by the whole class. 
The teacher's role was only to organize the debate, make sure the rules are correct and that everybody was involved in the discussion.

With the Experimental Group, focus was not only on the communicative aspect, but it included a more structural feature.

The lesson was initiated by a communicative task taken from a book by Mario Rinvolucri (1995: 92) entitled "Grammar Games: Cognitive, affective and drama activities for EFL students". In the activity "Defining Birds and Brothers" the students were first made aware of the idea of indefiniteness. They were paired, given birds worksheets and asked to write sentences defining them. After the time allocated that was 10 minutes, each pair proposed their definition which was written on the board and discussed (considering its grammatical accuracy) by the whole class. The same procedure took place while defining brothers and sisters. However, the male students started their definitions with either: a sister or sisters and the opposite was true.

After almost an hour of practicing indefiniteness, the students were introduced to definiteness. They were grouped into two equal teams competing against each other. Two students representing each group sat opposite each other. One held a group of pens with different colors and released them in the centre of a table they were both sitting at and asked the opposing student to take one or more pens according to the former's instructions. They carried on until the table was cleared. If at any time the student failed to follow the instruction, the one giving instructions marks a point for his/her team. The task went on for 30 minutes with a winning group. The losing team were asked to make further research about the notion of definiteness (since they found difficulties to follow the instructions) and report to the others in the following session.

In the second session, the experimental group's participants dealt with the same text of the control group students. Yet, after that task they were not asked to make research about the rules. The teacher's role was to explain those rules and make sure to give an exhaustive explanation of the rules of use of the English article system. At the end, a handout was given to the learners on which they wrote their names and had to fill in as many articles as possible during the time allocated which was 3 minutes. When they heard the word "pass", they did pass their paper to another student who in turn tried to fill in the rest of the articles. Later, the teacher announced the last exchange and each student corrected the paper they were left with. When peer correction ended, there was another whole class correction with the teacher whose role was not only as the monitor of the classroom but the tutor as well.

\subsection{Results of the Study}

In the following sections, we will present the results of the Test, Teachers' Questionnaire, and the Students' Questionnaire.

\subsubsection{The Test}


The data obtained from the Pre-test and Post-test was analyzed and summarized in the following tables:

Table 1: Control Group: Filing Gaps

\begin{tabular}{|l|c|c|c|c|}
\hline \multirow{2}{*}{\multicolumn{1}{|c|}{ Mean }} & \multicolumn{2}{c|}{ Right Answer } & \multicolumn{2}{c|}{ Wrong Answer } \\
\cline { 2 - 5 } & Pre-test & Post-test & Pre-test & Post-test \\
\hline All the answers & $67 \%$ & $72.66 \%$ & $33 \%$ & $27.33 \%$ \\
\hline Indef. Arti. "a/n" & $81 \%$ & $77 \%$ & $19 \%$ & $23 \%$ \\
\hline Zero Arti. "Ø" & $48 \%$ & $66 \%$ & $52 \%$ & $34 \%$ \\
\hline Def. Arti. "the" & $72 \%$ & $75 \%$ & $28 \%$ & $25 \%$ \\
\hline
\end{tabular}

We can observe from Table 1 a development in the students' performance. The students enhanced their understanding of the zero article " $\varnothing$ " and the definite article "the". Yet, their results decreased concerning the indefinite article " $\mathrm{a} / \mathrm{n}$ ". The difference between the percentages of the pre-test and post-test is $5.66 \%$ in all their right answers, $18 \%$ in using the zero article " $\varnothing "$ " correctly, and $03 \%$ in the definite article "the". However, there was a decrease in performing well as far as the indefinite article " $\mathrm{a} / \mathrm{n}$ " as the percentage dropped by $4 \%$.

Table 2: Control Group: Paragraph Writing

\begin{tabular}{|c|c|c|c|}
\hline \multicolumn{2}{|c|}{ Mean of all the right uses } & \multicolumn{2}{|c|}{ Mean of all the wrong uses } \\
\hline Pre-test & Post-test & Pre-test & Post-test \\
\hline $82.72 \%$ & $86.88 \%$ & $17.26 \%$ & $13.10 \%$ \\
\hline
\end{tabular}

The mean of all the students' right article use in the Pre-test is $82.72 \%$ while the average of all their correct article use in the Post-test is $86.88 \%$, which means that $04.16 \%$ is the difference and measure improvement of the Control Group's results when it comes to applying the results in their own writing.

Table 3: Experimental Group: Filling Gaps

\begin{tabular}{|l|c|c|c|c|}
\hline \multirow{2}{*}{ Mean } & \multicolumn{2}{|c|}{ Right Answer } & \multicolumn{2}{c|}{ Wrong Answer } \\
\cline { 2 - 5 } & Pre-test & Post-test & Pre-test & Post-test \\
\hline All the answers & $61.16 \%$ & $72.83 \%$ & $38.83 \%$ & $27.16 \%$ \\
\hline Indef. Arti. "a/n" & $70.50 \%$ & $74.50 \%$ & $29.50 \%$ & $25.50 \%$ \\
\hline Zero Arti. "Ø" & $55 \%$ & $66.50 \%$ & $45 \%$ & $33.50 \%$ \\
\hline Def. Arti. "the" & $58 \%$ & $77.50 \%$ & $42 \%$ & $22.50 \%$ \\
\hline
\end{tabular}

Table 3 reveals that the students' results have improved and the students have developed their understanding of the different article uses as the percentage of all their right answers in the Pre-test is $61.16 \%$ whereas it is $72.83 \%$ in the Post-test, marking a difference of $11.67 \%$. As for the indefinite article "a/n", the improvement is $04 \%$. The zero article " $\varnothing$ " has also witnessed 
a progress of $11.50 \%$ with $55 \%$ in the students' right answers in the Pre-test and $66.50 \%$ in the percentage of the Post-test. The dramatic change occurred with the definite article "the", in which the students achieved a development of $19.50 \%$ in using the definite article "the" correctly which is a quite noticeable progress. We can then deduce that the Communicative/Structural Approach is mostly successful in teaching the definite article "the".

Table 4: Experimental Group: Paragraph Writing

\begin{tabular}{|c|c|c|c|}
\hline \multicolumn{2}{|c|}{ Mean of all the right uses } & \multicolumn{2}{|c|}{ Mean of all the wrong uses } \\
\hline Pre-test & Post-test & Pre-test & Post-test \\
\hline $86.61 \%$ & $88.92 \%$ & $13.37 \%$ & $11.10 \%$ \\
\hline
\end{tabular}

The Experimental Group has shown a positive progress in using articles correctly in their own writing. The percentage of all their right article use in the Pre-test is $86.61 \%$ while it is $88.92 \%$ in the Post-test. As a result, one can conclude that the improvement of the students' right article use is $02.31 \%$ which is somehow disappointing when compared with the Control Group's progress.

\subsubsection{The Teachers' Questionnaire}

The teachers' questionnaire contains four sections and 24 questions. The questionnaire was distributed to 20 teachers in the English Department. The first section of the questionnaire provided information about our teachers. The average of their teaching experience is 10.40 years, yet it is only 5 years in teaching grammar, varying between first, second, and third year levels. The teachers who answered the questionnaire mainly hold the Master degree (10 teachers). 7 teachers got the Magister and 3 teachers got the Doctorate.

In the section "Teaching Grammar", the majority of the teachers (75\%) stated that they taught grammar eclectically. They explained that teaching grammar requires flexibility to adapt to the particular teaching situation and the Eclectic Approach suits any teaching/learning situation. Besides, it serves almost any objective or aim. They believe that one method is not enough to cope with the level, experience and needs of students. The difficulty of the task/rules or grammatical structures also influences the method to choose as well as the students' background knowledge of the nature of the grammatical rules. 55\% choose the method according to the material to be taught while $35 \%$ according to the students' proficiency level. $25 \%$ teach grammar according to the place and time allocated. $65 \%$ of the teachers who use the method depending on the nature of the grammatical aspect believe that it is ineffective to teach all the grammatical points by means of one method. Since each content is different from another one (difficulty), different materials and methods might be needed.

In the third section, the teachers were asked about knowing the concept or definition of the Communicative/Structural Approach. 9 teachers out of 20 
opted for "Yes" whereas 55\% are unaware of such an approach. Among 9teachers who are familiar with the Communicative/Structural Approach, $66.66 \%$ use it in teaching grammar. The teachers sometimes use the Communicative/Structural Approach for aspects of little interest (studentperceived), namely, aspects they think students already know about. It helps in attracting students' interest in what they teach: modals, articles, gerunds, prepositions, tenses (mainly perfective), and phrasal verbs as they are dependent on context. One teacher does not use the Communicative/Structural Approach because it is unsuitable for the grammar lessons, and another explained that it is not well understood. Other reasons mentioned by the teachers are time allocated for grammar lessons which is not enough (3 hours per week only) and the number of students per groups that is large and sometimes reaches 63 students in one group. The means and materials in the classroom are other factors preventing teachers to use such an approach. The latter are not really familiar with the approach. The majority of the students are uninterested that is the reason why they do not respond to the innovative tasks presented by their teachers.

In the last section "Teaching Articles and the Communicative/structural Approach", the majority of the teachers (75\%) agreed that teaching articles is a difficult task. $40 \%$ of the teachers who had found it difficult to teach articles explained that articles are taught in isolation, and only $20 \%$ stated that articles are unstressed and hard to be heard by students. Although only $15 \%$ of the teachers thought grammar should be taught inductively, $40 \%$ actually teach articles inductively. The teachers who teach articles deductively $(25 \%)$ prefer introducing the rules of use and meaning of the article system in order to avoid negative transfer and learn the difference between the mother tongue and the English rules. In order to suit the multiplicity of levels in the classroom and cover all the possible contexts difficult for the students, $35 \%$ of the teachers use an eclectic approach in teaching articles. Half of the teachers explained that students, when introduced to the lesson "articles", tend to express their difficulty. The teachers added other reactions like boredom and indifference as they think they already know everything about articles. They claim to be aware of the use of articles, but they fail to use them correctly when it comes to practice. All the teachers (100\%) assured that the Communicative/Structural Approach can help in teaching articles as it makes it easier for students to understand their use. Since this approach combines two major principles, it guarantees that students encounter instances in different authentic contexts and settings proposed to highlight the use of articles. Mixing the fun factor with the grammatical rules sparks interest in articles that could be addressed through challenging tasks and real-life situations. Therefore, focus is on form, meaningful use and communication. $50 \%$ of the teachers have already used the Communicative/Structural Approach to teach articles. The other teachers who 
have never used the Communicative/Structural Approach in teaching articles have various reasons. Two teachers have never used or heard of such an approach while the others have other constraints such as time allocated and the materials to use. However, the main factor is the students themselves. They are numerous in the classrooms, lazy, passive, introvert and they prefer written activities.

\subsubsection{The Students' Questionnaire}

The Students' Questionnaire was handed to 100 Second Year students in the Department of Letters and English at University "Des Frères Mentouri" who were chosen randomly. It was divided into 5 sections containing 19 questions. The aim of the Students' Questionnaire was to inspect the students' opinions in relation to their understanding of articles and the way of learning them.

The first section of the questionnaire deals with learning English. 51\% of the students have difficulties in learning English. $25.49 \%$ of them find it difficult because of grammar. They find it complicated and difficult to apply the rules even if they already know them. English includes a lot of rules and exceptions like with the case of articles. They are also insecure when it comes to learning the English tenses, infinitives, adjectives, and adverbs. They believe that it is mainly the way of teaching which hinders them to learn those rules appropriately.

In the second section, the students were asked whether grammar should be taught deductively, inductively, or eclectically. Half of the students $(50 \%)$ thought that an eclectic approach is best suited for teaching grammar. 59\% of the students stated that they learn grammar best when they are exposed to an authentic context containing a given rule which they are supposed to deduce and then the teacher provides more explanations with examples. When asked about the difficulties in learning grammar, half of the students found it difficult, mainly because the content is difficult (70\%). They find learning grammar a challenging task because of the difficulty of the rules. They added that all the rules seem to be alike but when it comes to using them, they do not apply to all the situations (a lot of exceptions). Beside the complexity and hardship of learning the grammatical rules, practice is not enough since they only use the language in the classroom and it takes time to internalize all the possible rules. Still, $10 \%$ of the students find the teacher's method unsuitable for their learning style. Only $10 \%$ of the students opted for "Articles" when asked about the most problematic grammatical aspect. In addition to that, the students find other aspects problematic, mainly, phrasal verbs, nouns, adjectives, and adverbs.

The students, in the third section, were asked about the Communicative/Structural Approach. 58\% thought their teachers used the Communicative/Structural Approach in teaching grammar, and $41.37 \%$ stated that their teachers always use it. 
"Learning Articles and the Communicative/Structural Approach" was the last section. Articles are difficult for $42 \%$ of the students because there are multiple uses for the same article. Concerning the most complicated article to learn, the definite article is complicated for $17 \%$ of the students because they are all the time confused when to use it, especially with plural and specific nouns. They stated that it has numerous uses which make it hard to know them all. In addition to that, it is used with a lot of proper nouns that must be learnt. Like the definite article, the indefinite article is hard to grasp for some learners $(29 \%)$ due to the multiplicity of contexts it might occur in. The other reason is that they cannot figure it out when a noun is countable or uncountable, definite or indefinite. As for the zero article, the students (46\%) find it confusing and its rules are not clear. They cannot really know when to use it or not, especially because of countable and uncountable nouns. Again, $54 \%$ of the students stated that their teachers teach articles eclectically. However, $40 \%$ of the students are taught deductively using a systematic and direct instruction. $70 \%$ discussed the difficulty of learning articles. They think that even after being familiar with this word category, they are unable to assimilate its correct use. That is the reason why they show more interest, or pay more attention and follow every word their teacher says during class. On the whole, $75 \%$ of the learners believe that the Communicative/Structural Approach can help in learning articles and that it makes a perfect combination as it serves both aims: learning and entertaining. It includes the fun factor followed by serious instruction. According to what they said, games are a good way to simplify rules and facilitate understanding them in a good sense of humor rather than other methods that make grammar learning quite dull and rigid. It is also an effective way to strengthen the teacher/student relationship and enables them to communicate weaknesses that might hinder the students to learn. $48 \%$ of the students confirmed that their teachers had used the Communicative/Structural Approach to teach articles.

\subsubsection{Overall Analysis}

Considering all the results of the Test, the Teachers' Questionnaire and Students' Questionnaire, we can conclude that the Communicative/Structural Approach has been proved to be successful in teaching the English article.

The Experimental Group's results in the Post-test in the first part (filling the gaps) are better than the Control Group's. The mean of the Experimental Group students right answers is $11.67 \%$ while it is only $05.66 \%$ for the latter. The Experimental Group students have enhanced their performance when it comes to using the indefinite article " $\mathrm{a} / \mathrm{n}$ " correctly by $04 \%$ while it is a decrease in the Control Group's results. In addition to that, $19.50 \%$ is the Experimental Group's progress in using the definite article "the" whereas it is only $03 \%$ for the Control Group. Concerning the writing part, the Control Group students have improved their results better than the Experimental Group learners although there were five students in the Experimental Group who used 
articles correctly in their paragraphs (100\%). The progress of the Control group was $04.16 \%$ against $02.31 \%$ only for the Experimental Group.

The teachers who answered the questionnaire insisted that grammar should be taught using an eclectic approach; more specifically articles are better assimilated and understood if taught by means of the Communicative/Structural Approach. Some of them already follow its principles in teaching grammar. As for the results of the students' questionnaire, they also confirmed that their teachers use the Communicative/Structural Approach in teaching them articles and it is an effective way in teaching grammar in general and articles specifically.

\section{Conclusion}

The Communicative/Structural Approach plays an important, effective, and major role in teaching the English article System. The results of both groups witnessed a development that can be said fulfilling the aims of our research. Hence, what we can deduce from the data obtained is that the students' grammatical competence, i.e. understanding and use of articles improved thanks to the systematic instruction provided by the teacher under the principles of the Communicative/Structural Approach.

\section{Bibliography}

Breen, M., \& Candlin, C.N. (1980). The Essentials of a Communicative Curriculum in Language Teaching. Applied Linguistics, 1(2), 89-112.

Cathcat, R. L. (1989). Authentic Discourse and the Survival English. TESOL Quarterly, 23(1), 105-126.

Communication. (2016). BusinessDictionary.com. Web Finance, Inc.

Communication. (2015). Merriam-Webster Dictionary. Merriam-Webster, Inc.

Cotter, C. (2016). How to Strike a Balance between Accuracy and Fluency. Heads up English.

Ekiert, M. (2004). Acquisition of the English Article System by Speakers of Polish in ESL and EFL Settings. Teachers College, Columbia University Working Papers in TESOL \& Applied Linguistics, 4(1), 1-23.

Master, P. (1994). The Effect of Systematic Instruction on Learning the English Article System. Perspectives on Pedagogical Grammar. Odlin Terence (Ed). Cambridge: Cambridge University Press, 229-252.

Nunan, D. (1991). Communicative Tasks and the Language Curriculum. TESOL Quarterly, 25(2), 279-295.

Richards, J. C. (2006). Communicative Language Teaching Today. Cambridge: Cambridge University Press.

Rinvolucri, M. (1995). Grammar Games: Cognitive, Affective and Drama Activities for EFL Students. Cambridge: Cambridge University Press.

Structural. (2016). The Free Dictionary. Farlex, Inc.

Structural. (2015). Merriam-Webster Dictionary. Merriam-Webster, Inc. 